\title{
An Important Dilemma in Treatment Planning: Implant or Endodontic Therapy?
}

\author{
Funda Kont Cobankara and Sema Belli \\ Selcuk University \\ Turkey
}

\section{Introduction}

One of the goals of a successful traditional dental practice has been the preservation and rehabilitation of a patient's natural dentition. Endodontic treatment has played a key role in the retention and restoration of teeth affected by pulp and/or periapical pathosis. In earlier times, diseased teeth would invariably be extracted. The improvements in modern endodontic techniques for conventional and later re-treatment and periradicular surgery has allowed for the retention of a number of teeth that would have been extracted in the past. Currently, the extraction of natural teeth has generally been considered undesirable and as a treatment choice of last resort when there are financial considerations and limited restorative options (John et al., 2007; Morris et al., 2009).

The development of osseointegrated implants has offered even more choices for dental practitioners and their patients in prosthetic rehabilitation for compromised teeth that require extraction. However, the choice of whether to retain a compromised tooth and restore it or to remove and possibly replace it is still unclear and presents as a common dilemma in restorative dentistry. In general, clinical decisions could become consistent and straightforward, if they are informed by unequivocal evidence, are supported by clear and accepted guidelines, and lead to recommended actions that are universally acceptable to patients and care providers (Pennington et al., 2009). However, especially in dental practice, a few decisions are not always so clear-cut. Although the traditional viewpoint is to retain teeth for as long as possible, this viewpoint has been challenged by emerging trends in implant dentistry, with implant replacements being touted as being equal to or even superior to the preservation of natural teeth.

In many cases, the choices are obvious. If a tooth is intact, there is no question that the endodontic treatment should be done, provided that the dentist has the skills required to do a satisfactory job. However, the choice of treatment for particularly compromised teeth may not be clear-cut in many situations. It must be realized that not only is the choice of the treatment controversial, but also the criteria for defining a tooth as "compromised" are controversial and subject to differences in interpretation. To discuss treatment of compromised teeth, a compromised tooth must be clearly defined and differentiated from a tooth with "end-stage" failure (Iqbal \& Kim, 2008). An "end-stage" tooth is defined by Iqbal \& Kim (2008) as a tooth with a pathologic state or structural deficiency that cannot be successfully repaired with reconstructive therapies, including root canal treatment and retreatment, and that continues to exhibit progressive pathologic changes and clinical 
dysfunction. In end-stage tooth failure, the treatment choices are obvious. However, the abundance of treatment alternatives for compromised teeth has caused dentists to make variable treatment recommendations for the teeth in the same and/or similar clinical situations. In particular, with implant dentistry rapidly gaining acceptance, the choice to retain a diseased and/or compromised tooth by root canal therapy or to extract the tooth and replace it with an implant-supported crown has become controversial and is still argued by opinion leaders and experts in both fields in the dental literature (Heffernan et al., 2003; Glickman, 2003; von Arx, 2005; Ruskin et al., 2005; Trope, 2005; Felton, 2005).

Nowadays, implant-supported prostheses have become the gold standard for the treatment of total or partial edentulism in most clinical scenarios (Avila et al., 2009). As a result, many practitioners have considered an implant-supported prosthesis as an alternative to the preservation of the natural dentition. This interest in implant dentistry has affected the treatment planning of not only end-stage teeth but also compromised teeth that may be more frequently extracted in favor of an implant placement. In truth, implants may be a better therapeutic alternative than performing more extensive conservative procedures in an attempt to save or maintain a compromised tooth. Nevertheless, an inadequate indication for implantation may result in the sacrifice of many sound salvageable teeth. Therefore, when the decision of whether to preserve a compromised tooth or to extract it and place an implant has to be made, a variety of factors (e.g., survival rates of endodontic treatment versus implant placement; patient's expectations, perception of treatment, and health conditions; time; financial status; esthetics; and clinician's proficiency and clinical background) should be considered.

\section{Factors influencing treatment planning}

\subsection{Survival rates}

One of the most-often debated components of this implant or endodontics dilemma is whether endodontic treatment and restoration can compete with a dental implant-borne prosthesis in terms of survival rates and success. Survival rates of endodontic treatment and implant placement are generally taken into account while choosing whether to extract or retain a compromised tooth. Both outcome measures for survival in the endodontic and implant literature are the same: retention of the tooth within the mouth (Iqbal \& Kim, 2007). In fact, it is important to keep in mind the fact that implant-based therapy and endodontic treatment are very different therapeutic options, given the variety of factors that can independently affect the diagnosis and outcomes of both modalities (White et al., 2006). One of the primary reasons for the variability of reported outcomes is the inconsistent definition of success in the evaluation criteria. Success in endodontics is very different from success for implants. The endodontic studies have applied strict definitions of success based on clinical and/or radiographic criteria (i.e., absence of apical radiolucency, looseness, and reduction in size of radiolucency) ( $\mathrm{Ng}$ et al., 2007), while implant studies have considered an implant to be successful if it is functional and present in the mouth without definite signs of absolute failure, such as peri-implant radiolucency or implant mobility (Doyle et al., 2006). The use of lenient success criteria in implant studies may translate to higher success rates, whereas the stringent criteria used in root canal studies may lead to lower success rates (Watson et al., 1999; Johnson \& Persson, 2001; Wennström et al., 2005, Doyle et al., 2006). Furthermore, operator differences exist between the two treatment modalities in the literature as well (Blicher et al., 2008). Implant studies generally report procedures completed by specialists, while many endodontic studies involve work performed by 
students or general dentist (Cheung, 2002; Salehrabi \& Rotstein 2004; Alley et al., 2004; White et al., 2006; Cohn, 2005; Trope, 2005). The average survival rate of teeth that are endodontically treated by a general dentist is $\sim 89.7 \%$ after 5 years; if the treatment is performed by a specialist, the survival rate increases to $98.1 \%$ (Alley et al., 2004). This difference underscores how specialty training can affect success outcomes. There are also fundamental differences in the oral environments of patients receiving either endodontic treatment or implant therapy. Implants tend to be placed in the context of good oral health, whereas endodontic treatment usually is performed in the presence of active disease (Spangberg, 2006; Iqbal \& Kim, 2007). Obviously, some standardization is needed to make a more informed and appropriate comparisons between the two treatment modalities (Blicher et al., 2008).

Stockhausen et al. (2011) investigated whether general dentists can appreciate the differences in the outcome measures between the implant and the endodontic literature and reported that a majority of respondents were unaware that a difference in criteria for success exists between the endodontic and implant literature.

Despite the fact that it might not be appropriate to compare endodontic treatment with implant placement due to the varying outcome measures and prognostic indicators in the literature (John et al., 2007), selecting the optimal treatment plan for each patient requires a critical comparison of the reported outcomes of these treatment modalities. While making a decision between endodontic treatment and implants, long-term success is still an important factor that must be considered by both dentist and patient, especially because a dental implant is an invasive procedure and involves the extraction of teeth.

A retrospective cross-sectional comparison of the initial nonsurgical endodontic treatment and single-tooth implants showed that endodontic and implant therapies resulted in an identical number of failures, and the implant group experienced a much greater incidence of post-operative complications (e.g., prosthetic repairs) (Doyle et al., 2006). When comparable criteria are applied to the outcome, survival rates of endodontic treatment and implant placement are found to be similar (John et al., 2007). Depending on the results of a metaanalysis study, Iqbal \& Kim (2007) reported that the outcomes for the two treatments were equivalent and that the decision to treat a compromised tooth endodontically or replace it with an implant must be based on factors other than treatment outcome. Consequently, because outcomes are similar with either treatment, it may be advised that the decisions should be based on other factors related to the tooth, the patient, and the clinician, such as the patient's informed decision concerning restorability, costs associated with the procedures, esthetics, potential adverse outcomes, and ethical factors.

In general, endodontic treatment that is done for the first time in a particular tooth has a higher long-term tooth survival rate (Imura et al., 2007). Also, the absence of periapical lesions, or the presence of smaller ones, has a better prognosis than larger lesions in terms of the success of endodontic treatment (Stoll et al., 2005). If an endodontically treated tooth presents persistent symptoms, retreatment of the affected tooth is a suitable option. Nevertheless, re-treatment of failed endodontic therapy is often complex. These procedures, in addition to being time-consuming and expensive, expose the patient to a significant decrease in the long-term predictability of any planned restoration(s) as valuable tooth structure has been lost leading to decreased structural integrity (Ruskin et al., 2005). In short, in cases where re-treated root canals are performed, the survival rates are substantially lower. However, these rates are slightly lower than those for implantsupported, single-tooth restorations (Noack et al., 1999; Ratner, 2001). 
Apical surgeries are considered as other options in the case of root canal treatment failure where re-treatment is not indicated (Nair, 1999). With respect to apical surgeries, apicoectomies have a success rate of $74 \%$ and a survival rate of $91 \%$ (Wang et al., 2004). A systematic review reported that the success rate of endodontic surgery $(64.2 \%)$ was significantly greater than the resurgery percentage of success (35.7\%) (Peterson \& Gutmann, 2001). However, apicoectomies do not always preclude the need for dental implants. In addition, buccal fenestrations created to gain access to the periapical area may not heal with an intact buccal plate of bone. Therefore, these procedures may compromise an implant site and precipitate the need for additional bone grafting when an implant is needed (Greenstein et al., 2008). Although there are differences in studies, a recent review of the literature concluded that endodontic treatment is the best option in many cases; however, dental implants provide a good alternative in certain cases in which the prognosis of maintaining the tooth is questionable or poor (Iqbal \& Kim, 2008).

\subsection{Patient factors}

With patients considering endodontic treatment or implant placement, the clinician should perform a complete informed-consent protocol, which includes a discussion of alternatives for care, the advantages and disadvantages of each option, the costs of each option and what will happen if nothing is done (Christensen, 1999; Graskemper, 2005; Sippy, 2006). Patientspecific factors influence the most appropriate treatment option. For example, when designing a dental treatment plan, a patient's expectations may bear more important than the clinical factors. Friedman \& Mor (2004) presented a scenario where a patient was asked if he wished to retain his hand after having sustained a complicated wrist fracture or would proceed to amputation and replacement with a functional prosthetic limb. Clearly, the patient would most likely choose to save his hand even if function and comfort were reduced. Therefore, the expectations of the patients have to be clearly identified and should be taken into account while making a decision for the treatment plan. If an extraction is indicated for a tooth after the initial clinical examination, but the patient wants to save it, the decision can be made to save the tooth; however, the patient should be informed about the possible consequences and potential risks associated with this decision (Avila et al., 2009).

Patients' perceptions of the psychological and physiological trauma related to each therapy may affect their decision. Many patients fear both the endodontic therapy and even the mere thought of any surgery because of the peri- or post-treatment pain. However, it should be considered that the pain experienced after endodontic treatment and implant surgery fell within the guidelines for adequate control of peri-operative pain (Iqbal \& Kim, 2008). Other factors that should be considered include the dental history, the cultural implications of the tooth loss, and the quality of life that such treatment would produce (Bader, 2001, 2002; Tang \& Naylor, 2005; Torabinejad \& Goodacre, 2006; White et al., 2006; Cohn, 2005; Christensen, 2006).

The patient's age is a distinct factor to be considered while making an initial treatment plan. In young people, implants are contraindicated until the growth phase is completed because the fixture will ankylose, resulting in infraocclusion (Brugnolo et al., 1996). Infraocclusion may cause changes in the gingival architecture around the implant, with esthetic implications (Cohn, 2005). However, endodontic treatment can be applied to patients in every age group. If the patient's age does not permit a permanent prosthesis or implant because of incomplete skeletal development, endodontic treatment can be advantageous for 
patients in their adolescent or childhood period by maintaining the height of the alveolar bone and allowing for the provision of an esthetically acceptable permanent restoration at a later age (Cobankara \& Ungor, 2007; Ferrazzano et al., 2010). In addition, it must be kept in mind that significant bone loss can be observed in younger patients receiving implant treatment by the time they reach old age (Bowles et al., 2010).

Knowledge of patient-related risk factors may assist the clinician in proper case-selection and treatment planning. For example, the patient's health condition is also an important factor when deciding between implant and endodontic therapy. Diabetes mellitus is often accompanied with systemic adverse sequelae, such as wound healing alterations, which may affect the osseointegration of dental implants or healing of periapical lesions. In one study, patients with diabetes showed a reduced likelihood of endodontic success, especially in cases with preoperative periradicular lesions (Fouad \& Burleson, 2003). In a matched case-control study, Doyle et al. (2007) noted that the outcomes for single-tooth implants and restored endodontically treated teeth were not significantly affected by diabetes; however, preoperative lesions were not reported. In addition, a recent one-year clinical outcome study reported no evidence of diminished clinical success or significant complications related to implant treatment in patients with diabetes (Turkyilmaz, 2010). Consequently, implants in patients with diabetes can be successful; however, it should be considered that the duration of diabetes might be an important factor in implant failure (Olson et al., 2000). Avila et al. (2009) suggested that extracting a tooth and subsequently performing an implant placement could be done in the presence of a controlled systemic condition, but they suggested that one should proceed with caution. If a patient has a systemic condition that is not properly controlled, tooth conservation is advised because a surgical procedure may present an unnecessary risk for the patient. It is a well-known fact that some special medical conditions, such as bleeding disorders or conditions related to the sequelae of radiation therapy, require tooth preservation and the avoidance of extractions or other surgical procedures. In such instances, endodontic treatment is often preferable to an implant.

In the implant studies, smoking is frequently identified as a risk indicator associated with failure (Vehemente et al., 2002; Strietzel et al., 2007; Huynh-Ba et al., 2008; Abt, 2009; Alissa \& Oliver, 2010); however, less information is available regarding the relation between the outcome of endodontic treatment and smoking. In one study, Marending et al. (2005) noted that smoking had no impact on the endodontic treatment outcome. Other authors suggested a possible negative influence of smoking on the prognosis of root canal-treated teeth, but this was mainly attributed to delayed bone healing and to an increased prevalence of periodontal disease and root caries in smokers (Duncan \& Pitt Ford, 2006). A recent study by Doyle et al. (2007) suggested that smokers had a lower success rate and more failures in both single-tooth implants and endodontic restorations.

In patients with high caries activity, especially activity that is possibly related to dry mouth as a common side effect of several medications (e.g., antihypertensives, diuretics, antidepressants, atropine, anticonvulsants, spasmolysants and appetite suppressants) or associated with certain syndromes (e.g., Sjögren), less effort will be made to maintain a compromised tooth, and implant treatment may be favored (Zitzmann et al., 2009). At the same time, the use of certain medications (such as biophosphonates) may limit the use of dental implants (Glickman, 2003; Starck \& Epker, 1995). If a patient has received intravenous bisphosphonates, a conservative non-surgical treatment is strongly recommended, and tooth conservation is advised because the prolonged use of bisphosphonates can cause a 
pathologic condition affecting the jaws called bisphosphonate-associated osteonecrosis (Avila et al., 2009).

Oral hygiene or compliance of patients also can affect the treatment options that are appropriate for a patient. Patients who are unlikely to maintain a high level of oral hygiene should not be considered for an implant (Koutsonikos, 1998; Bader, 2002). While excellent oral hygiene is always desirable, a less than optimum condition does not preclude endodontic treatment (Cohn, 2005). Peri-implant tissues are subject to mechanisms of infection similar to periodontal disease (Bullon et al., 2004); however, implant sites have been shown to be more difficult to keep clean and healthy than natural tooth sites (Chang et al., 1999). These findings suggest that implants are perhaps at greater risk for eventual loss than natural teeth, especially in patients who are already prone to periodontal disease (Tang \& Naylor, 2005).

Parafunctional habits of patients (such as bruxism) should also be addressed when choosing the appropriate treatment for patients (Cohn, 2005; Christensen, 2006). Because implants lack a periodontal ligament, they are at risk of damage from extreme mechanical forces developed as a result of parafunctional habits (Meffert, 1997; Misch, 2002; Blicher et al., 2008; Salvi \& Bragger, 2009).

\subsection{Duration of treatment}

Patients frequently inquire about the length of time required to complete treatment because the duration of the treatment plan and the amount of chair-time may also affect the decision for both the patient and the clinician ( $\mathrm{O}^{\prime} \mathrm{Neal} \&$ Butler, 2002; Cohn, 2005; Moiseiwitsch, 2002). When the time for completion of treatment was evaluated as the time from the beginning of the treatment until time to function, implant treatment had a longer time-tofunction than endodontic therapy (Doyle et al., 2006).

\subsection{Esthetic concerns}

Esthetic demand by the patients is of paramount importance for the clinicians. Therefore, when choosing the appropriate treatment, esthetic demands specific to the area of concern must be carefully considered (Davarpanah et al., 2000; Tang \& Naylor, 2005; Torabinejad \& Goodacre, 2006; White et al., 2006; Cohn, 2005; Christensen, 2006). When the potential for esthetic acceptability appears to be questionable with the planned implants and restorative therapy or especially in instances where the esthetic outcome is extremely important for the patient, retention of the affected tooth may be a better choice (Christensen, 2006). In such cases, failure to retain natural teeth and their subsequent replacement with implants can sometimes lead to unesthetic results. It has been stated that esthetic failures in implant dentistry are known to outnumber mechanical failures, especially in the anterior dentition (Goodacre et al., 2003). Many implant studies do not account for poor esthetics, implant malposition, soft tissue recession, bone maintenance, and unfavorable soft tissue configuration (Salinas \& Eckert, 2007). If the practitioner disregards esthetic risk factors, such as high patient expectations, a high smile line, poor gingival quality, poor papillary morphology, and low bone height, the patient may not be satisfied with implant treatment (Renouard \& Rangert, 1999). If these factors are not properly managed then predictable results are impossible to achieve (Tang \& Naylor, 2005).

A natural tooth often achieves better results for coronal shade matching; however, if the treatment plan involves crowning the natural tooth, an implant crown may allow for a 
better color match due to its thicker layer of porcelain (Torabinejad \& Goodacre, 2006). Also, if the natural tooth is misaligned with the natural dentition, an implant may produce a more esthetic result (White et al., 2006).

Soft tissue management is an important aspect of esthetic management in implant dentistry. The soft tissue biotype of the location influences the esthetic results (Torabinejad \& Goodacre, 2006; Cohn, 2005). When the periodontal biotype is thin but healthy around a natural tooth, then the preservation of the tooth through endodontic therapy might provide more appropriate soft tissue esthetics than a dental implant because a thin biotype is prone to recession (Torabinejad \& Goodacre, 2006; Greenstein et al., 2008). The placement of a foreign body in the bone may have a negative effect on the marginal bone height and has a direct effect on soft tissue contours (Choquet et al., 2001; Gastaldo et al., 2004). Therefore, the relationship between the final restoration and surrounding bone height should be envisaged while making a treatment plan to achieve successful esthetic soft tissue contours around the final restoration.

Papillary symmetry between the contralateral sides of the dentition is important for esthetics. However, a predictable, esthetic result is sometimes difficult to achieve because of the short papillae between implants when two or more adjacent implants are placed in the anterior maxilla (Elian et al., 2003). Therefore, to attain the best esthetics, if two adjacent implants are to be placed, modification of the treatment plan may be necessary. If possible, consideration should be given to saving one tooth to avoid short papillae (Greenstein et al., 2008). In some clinical situations, judicious, strategic extractions of compromised teeth, even of some teeth that can be retained, may facilitate an optimal restorative result and permit the placement of implants in ideal positions (Davarpanah et al., 2000; Greenstein, 2005). At the same time, if esthetics is not important, the decision of whether to conserve or extract a tooth becomes less critical.

\subsection{Financial status}

The financial factor may influence the decision-making process for both clinicians and patients. Traditional restorative procedures or implant-supported restorations are usually more expensive than maintaining a tooth. By using the mean fees charged by general practitioners as reported by the American Dental Association 2005 Survey of Dental Fees, Christensen (2006) reported that an implant-supported crown costs about twice that of an endodontically treated tooth restored with a crown. The patients are not always aware of the additional cost, especially in the case of dental implants (Avila et al., 2009). Possible adjunctive procedures before the implant placement, such as a variety of radiographs, mounted study casts, surgical stents, sinus lifts, bone grafts and membranes that would increase the cost of an implant, may be required and are generally not presented during the planning process. Rustemeyer \& Bremerich (2007) reported, after conducting a survey of 315 patients, that $61 \%$ had an unrealistic idea of the fees related to restorative therapy in which dental implants were used. Pennington et al. (2009) evaluated the cost-effectiveness of endodontic treatment for a maxillary incisor tooth in comparison with extraction and replacement with a bridge, denture or implant-supported restoration in a Markov model. After modeling the available clinical and cost data, they reported that the endodontic treatment and the orthograde re-treatment necessary when a root canal treatment fails are both cost-effective. If a surgical re-treatment is necessary, extending the life of the crown by replacment with a single implant is less cost effective (Pennington et al., 2009). In addition, 
in terms of post-procedural treatment requirements, the study by Doyle et al. (2007) demonstrated that implants required nearly 5 times more post-treatment interventions as compared with restored endodontically treated teeth. Kim \& Solomon (2011) evaluated the cost-effectiveness of four different treatment modalities (i.e., nonsurgical retreatment with restoration, endodontic microsurgery, extraction with fixed partial denture, and extraction with single implant-supported restoration) on a hypothetical clinical scenario of a failed endodontically treated first molar. According to these researchers, a single implant-supported restoration, despite its high survival rate, was the least cost-effective treatment option.

Consequently, from an economic standpoint, endodontic treatment might be a more favorable treatment option than implant-supported crowns.

\subsection{Clinician's proficiency and preference}

When dental implants were first introduced, it was mainly the oral surgeons who placed them. During the mid-1980s, periodontists began to place implants. More recently, a broader range of dental care providers, including general dentists, prosthodontists, and endodontists, are learning the skills of implant placement (Potter et al., 2009). Therefore, at present, there is yet no consensus on which expertise field should provide implant treatment and dental implant placement.

The decision to restore a diseased tooth with endodontic treatment or to extract the tooth and replace it with implant restoration might be influenced by the clinician's proficiency and clinical background. Bader \& Shugars (1993) have previously reported on this aspect of treatment planning for restorative treatments. According to this report, among clinicians, there were differences in the recommended treatment for individual teeth with specific conditions, and the main reason for the differences was the variation in the dentists' practice profiles (Bader \& Shugars, 1993).

If the patient feels that because of the expertise of the clinician, one or the other therapy has the greatest chance for success, then that therapy is the one that is chosen in that situation (Christensen, 2006). In addition, if the treatment options are presented in a biased manner to favor one option over the other, the patient is more likely to choose that treatment option (Foster \& Harrison, 2008). If a clinician believes that he/she is unable to save a tooth, tooth extraction and future prosthetic replacement will most likely be recommended (Avila et al., 2009). Although it is recognized that clinicians vary in their experience, skills, and interests, these factors should not dictate the treatment plan because other members of the dental team are available to provide specialized care on a referral basis (Iqbal \& Kim, 2008).

\subsection{Risk factors and/or complexity of each treatment modality}

Treatment of a compromised tooth requires the consideration of prosthodontic factors (such as the extent of caries, crown-root ratio, and dentinal wall thickness), endodontic factors (including root canal anatomy, periapical pathology, cause of primary failure in cases of retreatment, and the presence of root resorption or root fracture), and periodontal factors (such as mobility and furcation problems). If the longevity of a conserved tooth as related to these factors is questionable, the extraction of the tooth may sometimes be a better alternative than leaving the tooth in the mouth.

The type of restorations used for endodontically treated teeth and the quality of the coronal seal may have a greater impact on the long-term retention of treated teeth than the endodontic treatment itself (Saunders \& Saunders, 1994). In other words, endodontic 
therapy alone does not guarantee successful retention of the tooth or prevent its future loss. Extensively decayed or unrestorable tooth, tooth fracture, and periodontal disease, in conjunction with apical periodontitis, are more frequently indications for tooth extraction than the endodontic failure itself (Sorensen \& Martinoff, 1985; Sjogren et al., 1990; Vire, 1991; Caplan \& Weintraub, 1997; Chen et al., 2008).

A common issue with endodontically treated teeth is that when a failure does occur, the residual pathology can create potential problems for subsequent implant placement. Bone resorption and damage from infections of an endodontic origin can be extensive and require significant bone grafting and soft-tissue reconstruction (McGarry, 2008). However, it should be considered that endodontically treated teeth are associated with less complications and procedural interventions than implant-supported crowns and that complications associated with implant failure significantly impact a patient more negatively than when endodontically treated teeth fail (Morris et al., 2009).

While making a decision as to whether to retain and restore or to replace a tooth, the restorative prognosis of the tooth and the physical loading characteristics that it will be endured must also be kept in mind. For example, posts are often necessary to rebuild enough tooth structure to retain restorations when restoring compromised, root-filled teeth of the type that provide the subject for this discussion. However, the price for added retention may be an increased risk of damaged tooth structure (Caputo \& Standle, 1976). The long-term ability of the implant to retain a crown is superior to that of a natural tooth, particularly one that is endodontically treated and supporting a post and core (Ruskin et al., 2005). Therefore, compromised teeth treated with posts should be carefully used in areas where they may be critical to the survival of other reconstructions, such as abutments for bridges or removable partial dentures (Dawson \& Cardaci, 2006). However, implant treatment carries the risk of ongoing periodontal and occlusal complications, particularly esthetic problems. Some of the main advantages of an endodontic treatment compared to an implant-supported restoration are the proprioception and the adaptation under mechanical forces mediated by the periodontal ligament (Trulsson, 2006). In a recent study, endodontically treated teeth have been reported to have significantly higher maximum bite force, chewing efficiency, and total occlusal contact than single-tooth, implant-supported prostheses (Woodmansey et al., 2009).

The decision to extract or retain teeth affects the adjacent teeth, especially if they are to function as abutments for a fixed or removable partial denture. It has been reported that patients who used removable partial dentures over a 10 -year period lost $44 \%$ of the abutment teeth (Aquilino et al., 2001). However, there are no studies indicating whether the loss of the bordering teeth occurs when implants are inserted. In contrast, a large edentulous area may require the span of a fixed partial denture to be extended to incorporate teeth that require endodontic or periodontal treatment, thereby possibly compromising the long-term stability of the prosthesis (Greenstein et al., 2008). In such cases, implant treatment might be advised. For each patient, the strategic value of the tooth in relation to the overall oral structure and function must be evaluated; in addition, clinicians must consider how any treatment they perform will affect future treatments (Bader, 2001, 2002; Ruskin et al., 2005; Pothukuchi, 2006). Sometimes, retaining a compromised and diseased tooth may lead to continued bone loss, which could complicate future implant placement (Perel, 1991; Heithersay, 2000; Curtis et al., 2002; Matosian, 2003). 
One area of concern in recent years has been how implant placement would be affected by an adjacent tooth that had been treated endodontically. Some researchers suggest that implant failure may occur when the implant is positioned adjacent to teeth that are clinically symptomatic of periapical pathology or have radiographic periapical pathology (Shaffer et al., 1998; Tehemar, 1999; Brisman et al., 2001; Chou et al., 2010). According to these researchers, clinicians should be aware that if implant failure occurs in a tooth adjacent to one that has previously received endodontic therapy, further treatment or possible extraction of the previously treated tooth might be necessary before repeating the implant surgery. A recent study reported that the incidence of retrograde peri-implantitis might be reduced by increasing the distance between the implant and the adjacent tooth, and/or the duration from endodontic treatment to implant placement in the adjacent tooth (Zhou et al., 2009). However, some researchers suggested that the endodontic status of adjacent teeth has no effect on the prognosis of the implant (Shabahang et al., 2003; Doyle et al., 2007; Laird et al., 2008).

Local anatomy, such as proximity to the sinus or the type of bone, determines the potential need for additional procedures and/or whether the risk for complications will increase (Bader, 2001, 2002; Cohn, 2005; Torabinejad \& Goodacre, 2006). Any area with questionable or abnormal bone density, or the presence of potentially problematic anatomical structures, should persuade clinicians to retain teeth and choose the endodontic alternative (Christensen, 2006). Quality of bone is considered the most important determinant in the loss of implants (Vigolo \& Givani, 2000; Levin et al., 2006). However, in a recent study, Doyle et al. (2006) did not find the location of the restorative treatment a significant factor when comparing single-tooth implants and restored root-canal treated teeth.

The need for auxiliary procedures (for example, sinus lifts or grafts for implants and crown lengthening or orthodontic extrusion when restoring with endodontics) should be considered when determining the overall morbidity and potential for complications of each treatment option (Torabinejad \& Goodacre, 2006; White et al., 2006). If orthodontics continues to be performed in the future, one must remember that dental implants cannot undergo orthodontic movement (Wittlinger, 2007).

For successful long-term service, restored implants require regular follow-up, and the patient must realize that this option will not eliminate the need for further dental care (Blicher et al., 2008).

\section{Conclusion}

When choosing the appropriate treatment for patients, it should be kept in mind that every patient and situation is unique. Specific patient and/or clinician factors weigh heavily in choosing whether to perform tooth preservation procedures or extraction procedures with the option of implant-supported restoration. Saving teeth when reasonable is still the goal, but long-term outcomes need to be better delineated in the dental literature. In reality, no guide that is designed to aid in the decision to extract or save a compromised tooth can be perfect. However, because there are usually contradictory indications for dental implants and endodontic treatments in such teeth, there is a need for the development of guidelines. It is the responsibility of the clinician to make the final decision by considering the specific aspects of each case. The aim of both implant and endodontic therapy is to facilitate the rehabilitation of patients' natural dentition. However, it should not be forgotten that 
endodontic therapy is intended to retain teeth, whereas implant therapy is intended to replace missing teeth.

\section{References}

Abt, E. (2009). Smoking increases dental implant failures and complications. Evid Based Dent, Vol.10, No.3, pp.79-80.

Alissa, R. \& Oliver, R. (2010). Influence of prognostic risk indicators on osseointegrated dental implant failure: a matched case-control analysis. J Oral Implantol, (In press).

Alley, BS.; Kitchens, GG.; Alley, LW. \& Eleazer, PD. (2004). A comparison of survival of teeth following endodontic treatment performed by general dentists or by specialists. Oral Surg Oral Med Oral Pathol Oral Radiol Endod, Vol.98, No.1, pp.115-8.

Aquilino, SA.; Shugars, DA.; Bader, JD. \& White, BA. (2001). Ten-year survival rates of teeth adjacent to treated and untreated posterior bounded edentulous spaces. J Prosthet Dent, Vol.85, No.5, pp.455-60.

Avila, G.; Galindo-Moreno, P.; Soehren, S.; Misch, CE.; Morelli, T. \& Wang, HL. (2009). A novel decision-making process for tooth retention or extraction. J Periodontol, Vol.80, No.3, pp.476-91.

Bader, HI. (2001). Treatment planning for implants versus tooth retention: a contemporary dilemma. Dent Today, Vol.20, No.6, pp.47-50.

Bader, HI. (2002). Treatment planning for implants versus root canal therapy: a contemporary dilemma. Implant Dent, Vol.11, No.3, pp.217-23.

Bader, JD. \& Shugars, DA. (1993). Agreement among dentists' recommendations for restorative treatment. J Dent Res, Vol.72, No.5, pp.891-6.

Blicher, B.; Baker, D. \& Lin, J. (2008). Endosseous implants versus nonsurgical root canal therapy: a systematic review of the literature. Gen Dent, Vol.56, No.6, pp.576-80.

Bowles, WR.; Drum, M. \& Eleazer, PD. (2010). Endodontic and implant algorithms. Dent Clin North Am, Vol.54, No.2, pp.401-13.

Brisman, DL.; Brisman, AS. \& Moses, MS. (2001). Implant failures associated with asymptomatic endodontically treated teeth. J Am Dent Assoc, Vol.132, No.2, pp.191-5.

Brugnolo, E.; Mazzocco, C.; Cordioll, G. \& Majzoub, Z. (1996). Clinical and radiographic findings following placement of single-tooth implants in young patients--case reports. Int J Periodontics Restorative Dent, Vol.16, No.5, pp.421-33.

Bullon, P.; Fioroni, M.; Goteri, G.; Rubini, C. \& Battino, M. (2004). Immunohistochemical analysis of soft tissues in implants with healthy and peri-implantitis condition, and aggressive periodontitis. Clin Oral Implants Res, Vol.15, No.5, pp.553-9.

Caplan, DJ. \& Weintraub, JA. (1997). Factors related to loss of root canal filled teeth. J Public Health Dent, Vol.57, No.1, pp.31-9.

Caputo, AA. \& Standlee, JP. (1976). Pins and posts--why, when and how. Dent Clin North Am, Vol.20, No.2, pp.299-311.

Chang, M.; Wennström, JL.; Odman, P. \& Andersson, B. (1999). Implant supported singletooth replacements compared to contralateral natural teeth. Crown and soft tissue dimensions. Clin Oral Implants Res, Vol.10, No.3, pp.185-94.

Chen, SC.; Chueh, LH.; Hsiao, CK.; Wu, HP. \& Chiang, CP. (2008). First untoward events and reasons for tooth extraction after nonsurgical endodontic treatment in Taiwan. J Endod, Vol.34, No.6, pp.671-4. 
Cheung, GS. (2002). Survival of first-time nonsurgical root canal treatment performed in a dental teaching hospital. Oral Surg Oral Med Oral Pathol Oral Radiol Endod, Vol.93, No.5, pp.596-604.

Choquet, V.; Hermans, M.; Adriaenssens, P.; Daelemans, P.; Tarnow, DP. \& Malevez, C. (2001). Clinical and radiographic evaluation of the papilla level adjacent to singletooth dental implants. A retrospective study in the maxillary anterior region. J Periodontol, Vol.72, No.10, pp.1364-71.

Chou, TA.; Chang, YL.; Yu, LM.; Pan, WL.; Ju, YR. \& Chan, CP. (2010). An implant periapical lesion associated with an endodontic-periodontic lesion of an adjacent molar. J Dent Sci, Vol.5, No. 3, pp.171-5.

Christensen, GJ. (1999). Informing patients about treatment alternatives. J Am Dent Assoc, Vol.130, No.5, pp.730-2.

Christensen, GJ. (2006). Implant therapy versus endodontic therapy. J Am Dent Assoc, Vol.137, No.10, pp.1440-3.

Cobankara, FK., \& Ungor, M. (2007). Replantation after extended dry storage of avulsed permanent incisors: report of a case. Dent Traumatol, Vol. 23, No.4, pp.251-6.

Cohn, SA. (2005). Treatment choices for negative outcomes with non-surgical root canal treatment: non-surgical retreatment vs. surgical retreatment vs. implants. Endod Topics, Vol.11, No.1, pp.4-24.

Curtis, DA.; Lacy, A., Chu, R.; Richards, D.; Plesh, O; Kasrovi, P. \& Kao, R. (2002). Treatment planning in the 21st century: what's new? J Calif Dent Assoc, Vol.30, No.7, pp.503-10.

Davarpanah, M.; Martinez, H.; Tecucianu, JF.; Fromentin, O. \& Celletti, R. (2000). To conserve or implant: which choice of therapy? Int J Periodontics Restorative Dent, Vol.20, No.4, pp.412-22.

Dawson, AS. \& Cardaci, SC. (2006). Endodontics versus implantology: to extirpate or integrate? Aust Endod J, Vol.32, No.2, pp.57-63.

Doyle, SL, Hodges, JS., Pesun, IJ., Law, AS. \& Bowles, WR. (2006). Retrospective cross sectional comparison of initial nonsurgical endodontic treatment and single-tooth implants. J Endod, Vol.32, No.9, pp.822-7.

Doyle, SL.; Hodges, JS.; Pesun, IJ.; Baisden, MK. \& Bowles, WR. (2007). Factors affecting outcomes for single-tooth implants and endodontic restorations. J Endod, Vol.33, No.4, pp.399-402.

Duncan, HF. \& Pitt Ford, TR. (2006). The potential association between smoking and endodontic disease. Int Endod J, Vol.39, No.11, pp.843-54.

Elian, N.; Jalbout, ZN.; Cho, SC.; Froum, S. \& Tarnow, DP. (2003). Realities and limitations in the management of the interdental papilla between implants: three case reports. Pract Proced Aesthet Dent, Vol.15, No.10, pp.737-44.

Felton, DA. (2005). Implant or root canal therapy: a prosthodontist's view. J Esthet Restor Dent, Vol.17, No.4, pp.197-99.

Ferrazzano, GF.; Orlando, S.; Ingenito, A.; Tia, M. \& Sammartino, G. (2010). Tooth replantation as an alternative to dental implantology in adolescent patients. Eur J Paediatr Dent, Vol.11, No.4, pp.216-8.

Foster, KH. \& Harrison, E. (2008). Effect of presentation bias on selection of treatment option for failed endodontic therapy. Oral Surg Oral Med Oral Pathol Oral Radiol Endod, Vol.106, No.5, pp.e36-9. 
Fouad, AF. \& Burleson, J. (2003). The effect of diabetes mellitus on endodontic treatment outcome: data from an electronic patient record. J Am Dent Assoc, Vol.134, No.1, pp.43-51.

Friedman, S. \& Mor, C. (2004). The success of endodontic therapy--healing and functionality. J Calif Dent Assoc, Vol.32, No.6, pp.493-503.

Gastaldo, J.; Cury, PR. \& Sendyk, WR. (2004). Effect of the vertical and horizontal distances between adjacent implants and between a tooth and an implant on the incidence of interproximal papilla. J Periodontol, Vol.75, No.9, pp.1242-6.

Glickman, GN. (2003). Prognosis of endodontically treated teeth? Counterpoint. Quintessence Int, Vol.34, No.7, pp.560-1.

Goodacre, CJ., Bernal, G., Rungcharassaeng, K. \& Kan, JY. (2003). Clinical complications with implants and implant prostheses. J Prosthet Dent, Vol.90, No.2, pp.121-32.

Graskemper, JP. (2005). Informed consent: a stepping stone in risk management. Compend Educ Dent, Vol.26, No.4:286, pp.288-90.

Greenstein, G. (2005). Current interpretations of periodontal probing evaluations: diagnostic and therapeutic implications. Compend Contin Educ Dent, Vol.26, No.6, pp.381-98.

Greenstein, G.; Cavallaro, J. \& Tarnow, D. (2008) When to save or extract a tooth in the esthetic zone: a commentary. Compend Contin Educ Dent, Vol.29, No.3, pp.136-45.

Heffernan, M.; Martin, W. \& Morton, D. (2003). Prognosis of endodontically treated teeth? Point. Quintessence Int Vol.34, No.7, pp.558-60.

Heithersay, GS. (2000). Avoiding "the space" by the treatment of compromised teeth. Ann $R$ Australas Coll Dent Surg, Vol.15, (Oct), pp.247-51.

Huynh-Ba, G.; Friedberg, JR.; Vogiatzi, D. \& Ioannidou, E. (2008). Implant failure predictors in the posterior maxilla: a retrospective study of 273 consecutive implants. J Periodontol, Vol.79, No.12, pp.2256-61.

Imura, N.; Pinheiro, ET.; Gomes, BP.; Zaia, AA.; Ferraz, CC. \& Souza-Filho, FJ. (2007). The outcome of endodontic treatment: a retrospective study of 2000 cases performed by a specialist. J Endod, Vol.33, No.11, pp.1278-82.

Iqbal, MK. \& Kim, S. (2007). For teeth requiring endodontic treatment, what are the differences in outcomes of restored endodontically treated teeth compared to implant-supported restorations? Int J Oral Maxillofac Implants, Vol.22, No.Suppl, pp:96-116.

Iqbal, MK. \& Kim, S. (2008). A review of factors influencing treatment planning decisions of single-tooth implants versus preserving natural teeth with nonsurgical endodontic therapy. J Endod, Vol.34, No.5, pp.519-29.

John, V.; Chen, S. \& Parashos, P. (2007). Implant or the natural tooth-a contemporary treatment planning dilemma? Aust Dent J, Vol.52, No.1 Suppl, pp.138-50.

Johnson, RH. \& Persson, GR. (2001). A 3-year prospective study of a single-tooth implantprosthodontic complications. Int J Prosthodont, Vol.14, No.2, pp.183-9.

Kim, SG. \& Solomon, C. (2011). Cost-effectiveness of endodontic molar retreatment compared with fixed partial dentures and single-tooth implant alternatives. $J$ Endod, Vol. 37, No.3, pp. 321-5.

Koutsonikos, A. (1998). Implants: success and failure - a literature review. Ann R Australas Coll Dent Surg, Vol.14, No.Oct, pp.75-80. 
Laird, BS.; Hermsen, MS.; Gound, TG.; Al Salleeh, F.; Byarlay, MR.; Vogt, M. \& Marx, DB. (2008). Incidence of endodontic implantitis and implant endodontitis occurring with single-tooth implants: a retrospective study. J Endod, Vol.34, No.11, pp.1316-24.

Levin, L.; Sadet, P. \& Grossmann, Y. (2006). A retrospective evaluation of 1,387 single-tooth implants: a 6-year follow-up. J Periodontol, Vol.77, No.12, pp.2080-3.

Marending, M.; Peters, OA. \& Zehnder, M. (2005). Factors affecting the outcome of orthograde root canal therapy in a general dentistry hospital practice. Oral Surg Oral Med Oral Pathol Oral Radiol Endod, Vol.99, No.1, pp.119-24.

Matosian, GS. (2003). Treatment planning for the future: endodontics, post and core, and periodontal surgery-or an implant? J Calif Dent Assoc, Vol.31, No.4, pp.323-5.

McGarry, TJ. (2008). Creating the ideal prosthodontic platform: implants or endodontics in the aesthetic zone? Dent Today, Vol.27, No.8, pp.78-9.

Meffert, RM. (1997). Issues related to single-tooth implants. J Am Dent Assoc, Vol.128, No.10, pp.1383-90.

Misch, CE. (2002). The effect of bruxism on treatment planning for dental implants. Dent Today, Vol.21, No.9, pp.76-81.

Moiseiwitsch, J. (2002). Do dental implants toll the end of endodontics? Oral Surg Oral Med Oral Pathol Oral Radiol Endod, Vol.93, No.6, pp.633-4.

Morris, MF.; Kirkpatrick, TC.; Rutledge, RE. \& Schindler, WG. (2009). Comparison of nonsurgical root canal treatment and single-tooth implants. J Endod, Vol.35, No.10, pp.1325-30.

Nair, PN. (1999). Cholesterol as an aetiological agent in endodontic failures--a review. Aust Endod J, Vol.25, No.1, pp.19-26.

Ng, YL.; Mann, V.; Rahbaran, S.; Lewsey, J. \& Gulabivala, K. (2007). Outcome of primary root canal treatment: systematic review of the literature-part 1. Effects of study characteristics on probability of success. Int Endod J, Vol.40, No.12, pp.921-39.

Noack, N.; Willer, J. \& Hoffmann, J. (1999). Long-term results after placement of dental implants: longitudinal study of 1,964 implants over 16 years. Int J Oral Maxillofac Implants, Vol.14, No.5, pp.748-55.

Olson, JW.; Shernoff AF.; Tarlow, JL.; Colwell, JA.; Scheetz, JP. \& Bingham, SF. (2000). Dental endosseous implant assessments in a type 2 diabetic population: a prospective study. Int J Oral Maxillofac Implants, Vol.15, No.6, pp.811-8.

O'Neal, RB. \& Butler, BL. (2002). Restoration or implant placement: a growing treatment planning quandary. Periodontol 2000, Vol.30, pp.111-22.

Pennington, MW.; Vernazza, CR.; Shackley, P.; Armstrong, NT.; Whitworth, JM. \& Steele, JG. (2009). Evaluation of the cost-effectiveness of root canal treatment using conventional approaches versus replacement with an implant. Int Endod J, Vol.42, No.10, pp.874-83.

Perel, ML. (1991). Are we needlessly retaining 'hopeless' teeth? Dent Implantol Update, Vol.2, No.1, pp.1, 12.

Peterson, J. \& Gutmann, JL. (2001). The outcome of endodontic resurgery: a systematic review. Int Endod J, Vol.34, No.3, pp.169-75.

Pothukuchi, K. (2006). Case assessment and treatment planning: what governs your decision to treat, refer or replace a tooth that potentially requires endodontic treatment? Aust Endod J, Vol.32, No.2, pp.79-84. 
Potter, KS.; McQuistan, MR.; Williamson, AE.; Qian, F. \& Damiano, P. (2009). Should endodontists place implants? A survey of U.S. endodontists. J Endod, Vol.35, No.7, pp.966-70.

Ratner, BD. (2001). Replacing and renewing: synthetic materials, biomimetics, and tissue engineering in implant dentistry. J Dent Educ, Vol.65, No.12, pp.1340-7.

Renouard, F. \& Rangert, B. (1999). Risk factors in implant dentistry: simplified clinical analysis for predictable treatment (1 ${ }^{\text {st }}$ ed.), Quintessence, (ISBN-13: 978-0867153552),Copenhagen, pp.30-7.

Ruskin, JD.; Morton, D.; Karayazgan, B. \& Amir, J. (2005). Failed root canals: the case for extraction and immediate implant placement. J Oral Maxillofac Surg, Vol.63, No.6, pp.829-31.

Rustemeyer, J. \& Bremerich, A. (2007). Patients' knowledge and expectations regarding dental implants: assessment by questionnaire. Int J Oral Maxillofac Surg, Vol.36, No.9, pp.814-7.

Salehrabi, R. \& Rotstein, I. (2004). Endodontic treatment outcomes in a large patient population in the USA: an epidemiological study. J Endod, Vol.30, No.12, pp.846-50.

Salinas, TJ. \& Eckert, SE. (2007). In patients requiring single-tooth replacement, what are the outcomes of implant- as compared to tooth-supported restorations? Int J Oral Maxillofac Implants, Vol.22, No.Suppl, pp.71-95.

Salvi, GE. \& Bragger, U. (2009). Mechanical and technical risks in implant therapy. Int J Oral Maxillofac Implants, Vol.24, No.Suppl, pp.69-85.

Saunders, WP. \& Saunders, EM. (1994). Coronal leakage as a cause of failure in root-canal therapy: a review. Endod Dent Traumatol, Vol.10, No.3, pp.105-8.

Shabahang, S.; Bohsali, K.; Boyne, PJ.; Caplanis, N.; Lozada, J. \& Torabinejad, M. (2003). Effect of teeth with periradicular lesions on adjacent dental implants. Oral Surg Oral Med Oral Pathol Oral Radiol Endod, Vol.96, No.3, pp.321-6.

Shaffer, MD.; Juruaz, DA. \& Haggerty, PC. (1998). The effect of periradicular endodontic pathosis on the apical region of adjacent implants. Oral Surg Oral Med Oral Pathol Oral Radiol Endod, Vol.86, No.5, pp.578-81.

Sippy, RE. (2006). Informed consent: why you need more than a signature. Dent Assist, Vol.75, No.2:28, pp.30-1.

Sjogren, U., Hagglund, B., Sundqvist, G. \& Wing, K. (1990). Factors affecting the long-term results of endodontic treatment. J Endod, Vol.16, No.10, pp.498-504.

Sorensen, JA. \& Martinoff, JT. (1985). Endodontically treated teeth as abutments. J Prosthet Dent, Vol.53, No.5, pp.631-6.

Spangberg, LS. (2006). To implant, or not to implant; That is the question. Oral Surg Oral Med Oral Pathol Oral Radiol Endod, Vol.101, No.6, pp.695-6.

Starck, WJ. \& Epker, BN. (1995). Failure of osseointegrated dental implants after diphosphonate therapy for osteoporosis: a case report. Int J Oral Maxillofac Implants, Vol.10, No.1, pp.74-8.

Stockhausen, R.; Aseltine, R Jr.; Matthews, JG. \& Kaufman, B. (2011). The perceived prognosis of endodontic treatment and implant therapy among dental practitioners. Oral Surg Oral Med Oral Pathol Oral Radiol Endod, Vol.111, No.2, pp.e42-7.

Stoll, R., Betke, K. \& Stachniss, V. (2005). The influence of different factors on the survival of root canal fillings: a 10-year retrospective study. J Endod, Vol.31, No.11, pp.783-90. 
Strietzel, FP.; Reichart, PA.; Kale, A.; Kulkarni, M.; Wegner, B. \& Küchler, I. (2007). Smoking interferes with the prognosis of dental implant treatment: a systematic review and meta-analysis. J Clin Periodontol, Vol.34, No.6, pp.523-44.

Tang, CS. \& Naylor, AE. (2005). Single-unit implants versus conventional treatments for compromised teeth: a brief review of the evidence. J Dent Educ, Vol.69, No.4, pp.414-8.

Tehemar, SH. (1999). Factors affecting heat generation during implant site preparation: a review of biologic observations and future considerations. Int J Oral Maxillofac Implants, Vol.14, No.1, pp.127-36.

Torabinejad, M. \& Goodacre, CJ. (2006). Endodontic or dental implant therapy: the factors affecting treatment planning. J Am Dent Assoc, Vol.137, No.7, pp.973-7.

Trope, M. (2005). Implant or root canal therapy: an endodontist's view. J Esthet Restor Dent, Vol. 17, No.3, pp.139-40.

Trulsson, M. (2006). Sensory-motor function of human periodontal mechanoreceptors. J Oral Rehabil, Vol.33, No.4, pp.262-73.

Turkyilmaz, I. (2010). One-year clinical outcome of dental implants placed in patients with type 2 diabetes mellitus: a case series. Implant Dent, Vol.19, No.4, pp.323-9.

Vehemente, VA.; Chuang, SK.; Daher, S.; Muftu, A. \& Dodson, TB. (2002). Risk factors affecting dental implant survival. J Oral Implantol, Vol.28, No.2, pp.74-81.

Vigolo, P. \& Givani, A. (2000). Clinical evaluation of single-tooth mini-implant restorations: a five-year retrospective study. J Prosthet Dent, Vol.84, No.1, pp.50-4.

Vire, DE. (1991). Failure of endodontically treated teeth: classification and evaluation. J Endod, Vol.17, No.7, pp.338-42.

von Arx, T. (2005). Failed root canals: the case for apicoectomy (periradicular surgery). J Oral Maxillofac Surg,Vol. 63, No.6, pp.832-837.

Wang, N.; Knight, K.; Dao, T. \& Friedman, S. (2004). Treatment outcome in endodontics-The Toronto Study. Phases I and II: apical surgery. J Endod, Vol.30, No.11, pp.751-61.

Watson, CJ.; Tinsley, D.; Ogden, AR.; Russell, JL.; Mulay, S. \& Davison, EM. (1999). A 3 to 4 year study of single tooth hydroxylapatite coated endosseous dental implants. $\mathrm{Br}$ Dent J, Vol.24, No.187 (2), pp.90-4.

Wennström, JL.; Ekestubbe, A.; Gröndahl, K.; Karlsson, S. \& Lindhe, J. (2005). Implantsupported single-tooth restorations: a 5-year prospective study. J Clin Periodontol, Vol.32, No.6, pp.567-74.

White, SN.; Miklus, VG.; Potter, KS.; Cho, J. \& Ngan, AY. (2006). Endodontics and implants, a catalog of therapeutic contrasts. J Evid Based Dent Pract, Vol.6, No.1, pp.101-9.

Wittlinger, E. (2007). Implants, endodontics and orthodontics. J Am Dent Assoc, Vol.138, No.2, pp.148.

Woodmansey, KF.; Ayik, M.; Buschang, PH.; White, CA. \& He, J. (2009). Differences in masticatory function in patients with endodontically treated teeth and singleimplant-supported prostheses: a pilot study. J Endod, Vol.35, No.1, pp.10-4.

Zhou, W.; Han, C.; Li, D.; Li, Y.; Song, Y. \& Zhao, Y. (2009). Endodontic treatment of teeth induces retrograde peri-implantitis. Clin Oral Implants Res, Vol.20, No.12, pp.1326-32.

Zitzmann, NU.; Krastl, G.; Hecker, H.; Walter, C. \& Weiger R. (2009). Endodontics or implants? A review of decisive criteria and guidelines for single tooth restorations and full arch reconstructions. Int Endod J, Vol.42, No.9, pp.757-74. 


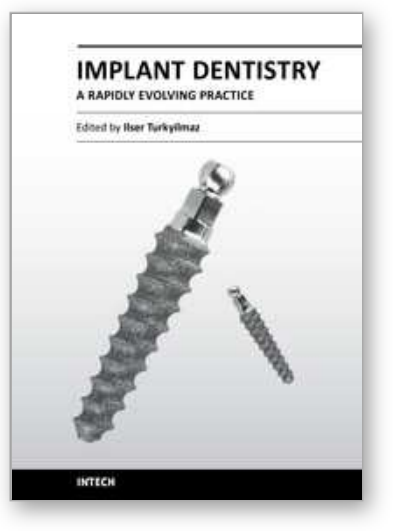

\author{
Implant Dentistry - A Rapidly Evolving Practice \\ Edited by Prof. Ilser Turkyilmaz
}

ISBN 978-953-307-658-4

Hard cover, 544 pages

Publisher InTech

Published online 29, August, 2011

Published in print edition August, 2011

Implant dentistry has come a long way since Dr. Branemark introduced the osseointegration concept with endosseous implants. The use of dental implants has increased exponentially in the last three decades. As implant treatment became more predictable, the benefits of therapy became evident. The demand for dental implants has fueled a rapid expansion of the market. Presently, general dentists and a variety of specialists offer implants as a solution to partial and complete edentulism. Implant dentistry continues to evolve and expand with the development of new surgical and prosthodontic techniques. The aim of Implant Dentistry - A Rapidly Evolving Practice, is to provide a comtemporary clinic resource for dentists who want to replace missing teeth with dental implants. It is a text that relates one chapter to every other chapter and integrates common threads among science, clinical experience and future concepts. This book consists of 23 chapters divided into five sections. We believe that, Implant Dentistry: A Rapidly Evolving Practice, will be a valuable source for dental students, post-graduate residents, general dentists and specialists who want to know more about dental implants.

\title{
How to reference
}

In order to correctly reference this scholarly work, feel free to copy and paste the following:

Funda Kont Cobankara and Sema Belli (2011). An Important Dilemma in Treatment Planning: Implant or Endodontic Therapy?, Implant Dentistry - A Rapidly Evolving Practice, Prof. Ilser Turkyilmaz (Ed.), ISBN: 978953-307-658-4, InTech, Available from: http:/www.intechopen.com/books/implant-dentistry-a-rapidly-evolvingpractice/an-important-dilemma-in-treatment-planning-implant-or-endodontic-therapy-

\section{INTECH}

open science | open minds

\section{InTech Europe}

University Campus STeP Ri

Slavka Krautzeka 83/A

51000 Rijeka, Croatia

Phone: +385 (51) 770447

Fax: +385 (51) 686166

www.intechopen.com

\section{InTech China}

Unit 405, Office Block, Hotel Equatorial Shanghai

No.65, Yan An Road (West), Shanghai, 200040, China 中国上海市延安西路65号上海国际贵都大饭店办公楼405单元

Phone: +86-21-62489820

Fax: +86-21-62489821 
(C) 2011 The Author(s). Licensee IntechOpen. This chapter is distributed under the terms of the Creative Commons Attribution-NonCommercialShareAlike-3.0 License, which permits use, distribution and reproduction for non-commercial purposes, provided the original is properly cited and derivative works building on this content are distributed under the same license. 